\title{
PENGARUH PERATURAN BANK INDONESIA TENTANG KREDIT UMKM TERHADAP TOTAL KREDIT, RASIO KREDIT UMKM, RISIKO, EFISIENSI DAN PROFITABILITAS BANK PEMBANGUNAN DAERAH
}

\author{
Bagus Santosa \\ Program Studi Magister Manajemen Universitas Tarumanagara \\ bsantosa.waterorg@gmail.com \\ Yanuar \\ Program Studi Magister Manajemen Universitas Tarumanagara \\ Masuk : 02-10-2019, revisi : 04-11-2019 diterima untuk diterbitkan : 05-11-2019
}

\begin{abstract}
This research aims to analyze the effect of Bank of Indonesia Regulation on Micro, Small, and Medium Enterprises (MSME) loans towards the Loan Disbursed, MSME Loan Ratio, Risk, Efficiency, and Profitability of Regional Development Banks. This research analyzes the financial data from 10 BPDs over 10 years period to understand the Loan Disbursed, MSME Loan Ratio, Risk, Efficiency, and Profitability of the BPDs before and after the implementation of Regulation Number 14/22/PBI/2012. The financial data were analyzed using the Paired-Sample t-test. Findings show that the overall loan disbursed by BPDs in the period of 2013-2017 or after the Regulation on MSME loans was implemented, is higher than that in the period of 2008-2012 or before the regulation was implemented. However, while the regulation aims to increase the MSME loan disbursed by the banks, the MSME Loan Ratio in the period of 2013-2017 was lower than that in the period of 2008-2012. The Risk, measured by Non-Performing Loan, in the period of 2013-2017 was also increased. The regulation also affects the profitability of the BPDs negatively. The Efficiency, measured by Operating Expenses Operating Income, was not significantly affected by the regulation. The results may inform the regulators to assist the BPDs in responding to the regulation so it could affect BPDs in a more positive way. This may also inform the banks on their financial conditions so they can plan for strategic approaches and develop appropriate schemes on disbursing MSME loans.
\end{abstract}

Keywords : Bank of Indonesia Regulation; Micro, Small, and Medium Enterprises (MSME) loans; Risk; Efficiency; Profitability; Regional Development Banks (BPD)

\section{PENDAHULUAN \\ Latar Belakang}

Seiring dengan pertumbuhan ekonomi daerah, Bank Pembangunan Daerah (BPD) melakukan pengembangan layanan yang salah satunya melalui penyaluran berbagai produk kredit (Lisdayanti dkk, 2013). Salah satu sektor kredit yang dikembangkan oleh perbankan adalah sektor kredit usaha-usaha mikro, kecil dan menengah (UMKM). Berkaitan dengan peraturan BI dalam penyaluran kredit oleh Bank, di awal tahun 2013, Bank Indonesia memperkenalkan sebuah peraturan Bank Indonesia (PBI Nomor 14/22/PBI/2012 dan revisinya PBI Nomor 17/12/PBI/2015) yang mewajibkan pemberian kredit oleh bank umum, termasuk BPD, kepada usaha-usaha mikro, kecil dan menengah (UMKM) sebesar minimal 20\% dari total portofolio kredit pada tahun 2018. BI membagi pelaksanaan peraturan ini menjadi beberapa tahap. Antara tahun 2013 dan 2014, bank diperbolehkan untuk menyalurkan kredit kepada UMKM sebanyak yang mereka mampu. Rasio kredit baru diberlakukan mulai tahun 2015 ke atas, sebagai berikut: Tahun 2015 - Rasio kredit UMKM terhadap total kredit minimal 5\%; Tahun 2016 - Rasio kredit UMKM terhadap total kredit minimal 10\%; Tahun 2017 - Rasio 
kredit UMKM terhadap total kredit minimal 15\%; Tahun 2018 - Rasio kredit UMKM terhadap total kredit minimal $20 \%$.

BI akan memberikan reward bagi bank yang dapat memenuhi target penyaluran portofolio kredit UMKM dan mengenakan sanksi administratif bagi bank yang tidak memenuhi target tahunan penyaluran portofolio kredit mereka. Reward yang diberikan berupa pelonggaran batas atas LFR (Loan to Funding ratio) hingga menjadi 94\% hanya berlaku bagi bank yang sudah memenuhi pencapaian tertentu Kredit UMKM dengan kualitas kredit yang baik. Sedangkan, tindakan disipliner bagi bank yang tidak mencapai target penyaluran kredit UMKM bisa berupa teguran tertulis, denda atau merekomendasikan kepada OJK sebagai otoritas pengawas bank untuk melakukan tindakan lebih lanjut. Beberapa bank mungkin tidak akan naik ke kategori atau "BUKU" yang lebih tinggi sampai mereka memenuhi target kredit UMKM mereka. Ini akan membatasi kegiatan usaha dan layanan bank. Berkaitan dengan adanya kewajiban Bank dalam penyaluran portofolio kredit khususnya pada kredit UMKM sejak tahun 2013, penelitian ini bertujuan menganalisis apakah ketentuan PBI Nomor 14/22/PBI/2012 tersebut berpengaruh terhadap total kredit yang disalurkan (loans), rasio penyaluran kredit UMKM, risiko, efisiensi dan profitabilitas Bank Pembangunan Daerah. Risiko dikur dengan NPL (non-performing loans), efisiensi diukur dengan BOPO (biaya operasional per pendapatan operasional), dan profitabilitas diukur dengan ROA (return on assets).

\section{Tujuan Penelitian}

Penelitian ini bertujuan untuk mengetahui apakah berlakunya PBI Nomor 14/22/PBI/2012 tentang ketentuan penyaluran kredit UMKM berpengaruh terhadap total kredit, rasio kredit UMKM, risiko, efisiensi dan profitabilitas Bank Pembangunan Daerah pada periode 2008-2012, yaitu sebelum ketentuan ini berlaku, dan periode 2013-2017, setelah ketentuan ini berlaku. Hasil penelitian ini diharapkan dapat dijadikan sebagai bahan pertimbangan dalam pengambilan keputusan yang berkaitan dengan pilihan strategis dalam hal penyaluran kredit UMKM untuk peningkatan profitabilitas BPD. Bagi regulator yang terkait dalam sistem perbankan, penelitian ini diharapkan dapat dijadikan masukan dalam pembuatan peraturan tentang usaha perbankan, khususnya mengenai keputusan strategis bank, risiko bagi perbankan di Indonesia, dan tingkat penyaluran kredit UMKM guna memaksimalkan kinerja bank umum, termasuk di dalamnya bank pembangunan daerah.

\section{TINJAUAN PUSTAKA}

\section{Bank Pembangunan Daerah}

Bank Pembangunan Daerah menurut fungsinya dikategorikan sebagai bagian dari bank umum (Siamat, 2004). Dengan adanya UU No. 13/1962 ditetapkan ketentuan-ketentuan pokok bank pembangunan daerah (BPD), mengenai kedudukan kelembagaannya BPD berada di dalam lingkungan Depdagri, sedangkan untuk aspek teknis perbankan dan teknis perusahaannya, bank-bank tersebut mendapat pengawasan dan bimbingan dari BI dan Asbanda (Asosiasi Bank Pembangunan Daerah). Saat ini ada 27 BPD yang ada di Indonesia, rata-rata setiap provinsi mempunyai satu BPD tetapi ada juga BPD yang harus melayani dua provinsi.

\section{Peraturan Bank Indonesia tentang Kredit UMKM}

Berkaitan dengan peraturan BI dalam penyeluran kredit oleh Bank, di awal tahun 2013, Bank Indonesia memperkenalkan sebuah peraturan Bank Indonesia (PBI Nomor 14/22/PBI/2012 dan revisinya PBI Nomor 17/12/PBI/2015) yang mewajibkan pemberian kredit oleh bank umum, termasuk BPD, kepada usaha-usaha mikro, kecil dan menengah (UMKM). Pencapaian rasio pemberian Kredit atau Pembiayaan UMKM dihitung pada setiap akhir tahun. Pencapaian ini dilakukan secara bertahap, sebagai berikut:

a. Tahun 2013: rasio Kredit UMKM terhadap total Kredit sesuai kemampuan Bank; 
b. Tahun 2014: rasio Kredit UMKM terhadap total Kredit sesuai kemampuan Bank;

c. Tahun 2015: rasio Kredit UMKM terhadap total Kredit paling rendah 5\%;

d. Tahun 2016: rasio Kredit UMKM terhadap total Kredit paling rendah 10\%;

e. Tahun 2017: rasio Kredit UMKM terhadap total Kredit paling rendah 15\%;

f. Tahun 2018: rasio Kredit UMKM terhadap total Kredit paling rendah 20\%.

BI akan mengenakan sanksi administratif bagi bank yang tidak memenuhi target tahunan penyaluran portofolio kredit mereka. Tindakan disipliner ini bisa berupa teguran tertulis, denda atau merekomendasikan kepada OJK sebagai otoritas pengawas bank untuk melakukan tindakan lebih lanjut. Beberapa bank mungkin tidak akan naik ke kategori atau "BUKU" yang lebih tinggi sampai mereka memenuhi target kredit UMKM mereka. Ini akan membatasi kegiatan usaha dan layanan bank.

\section{Pengertian Usaha Mikro, Kecil dan Menengah (UMKM)}

Usaha Mikro adalah usaha produktif milik orang atau perseorangan dan/atau badan usaha perseorangan yang mempunyai kriteria sebagai berikut: memiliki kekayaan paling banyak Rp.50.000.000,00 atau memiliki hasil penjualan tahunan paling banyak Rp.300.000.000,00. Usaha Kecil. Usaha kecil adalah usaha ekonomi produktif yang berdiri sendiri yang dilakukan oleh orang perseorangan atau badan usaha yang memiliki kekayaan bersih lebih dari Rp.50.000.000,00 sampai dengan paling banyak Rp.500.000.000,00 tidak termasuk tanah dan bangunan tempat usaha, atau memiliki penjualan tahunan lebih dari Rp.300.000.000,00 sampai dengan paling banyak Rp.2.500.000.000,00. Usaha Menengah. Usaha Menengah adalah usaha ekonomi produktif yang berdiri sendiri, yang dilakukan oleh orang perseorangan atau badan usaha yang memiliki kekayaan bersih lebih dari Rp.500.000.000,00 sampai dengan paling banyak Rp.10.000.000.000,00 tidak termasuk tanah dan bangunan tempat usaha, atau memiliki hasil penjualan tahunan lebih dari Rp.2.500.000.000,00 sampai dengan paling banyak Rp.50.000.000.000.,00.

\section{METODOLOGI PENELITIAN}

\section{Sumber dan Pengumpulan Data}

Data yang digunakan dalam penelitian ini merupakan data sekunder yang diperoleh dari laporan tahunan (annual report) yang telah diaudit dari BPD periode tahun 2008-2017. Terdapat 10 BPD yang dijadikan sampel penelitian dengan 4 BPD berada di pulau Jawa dan 6 BPD di luar pulau Jawa. Adapun 10 BPD tersebut adalah Bank BJB, Bank Jateng, Bank Jatim, Bank DKI, Bank Nagari, Bank Sumut, Bank Sumsel-Babel, Bank Sulselbar, Bank Kaltimtara dan Bank Papua. Data yang digunakan pada penelitian ini adalah data panel yang terdiri dari 100 unit observasi, yang merupakan penggabungan dari data 10 Bank Pembangunan Daerah selama 10 tahun. BPD Sampel telah menyalurkan kredit UMKM dan memiliki asset dalam kategori BUKU-2 atau BUKU-3.

\section{Variabel Penelitian dan Operasionalisasi Variabel}

Variabel bebas dalam penelitian ini adalah Pemberlakuan PBI Nomor 14/22/PBI/2012 tentang Ketentuan "Penyaluran Portofolio pada Kredit UMKM". Data yang digunakan pada penelitian ini adalah data panel yang terdiri dari 100 unit observasi, yang merupakan penggabungan dari data 10 Bank Pembangunan Daerah selama 10 tahun yaitu tahun 20082012 yaitu sebelum PBI Nomor 14/22/PBI/2012 tentang Ketentuan "Penyaluran Portofolio pada Kredit UMKM" berlaku dan tahun 2013-2017 setelah PBI Nomor 14/22/PBI/2012 berlaku. Sementara itu, variabel terikat dalam penelitian ini adalah sebagai berikut:

a) Total Kredit. Total kredit adalah jumlah penyaluran total kredit seluruhnya (UMKM dan non-UMKM termasuk penyaluran sektor retail lainnya dan kredit korporasi).

b) Rasio (Persentase) Kredit UMKM terhadap Total Kredit. Perhitungan rasio (persentase) kredit UMKM terhadap total kredit dihitung pada setiap akhir tahun. Rasio ini didapat 
dari membagi jumlah penyaluran kredit yang dikategorikan dalam penyaluran sektor UMKM dibagi dengan jumlah penyaluran total kredit seluruhnya.

c) NPL

$$
\text { NPL }=\frac{\text { Non-performing Loan }}{\text { Total Loans }} \times 100 \%
$$

Perhitungan non-performing loan (NPL) secara umum ditunjukkan seperti di atas. NPL sendiri memperlihatkan besarnya persentase kredit macet di suatu bank..

d) $\mathrm{BOPO}$

$$
\mathrm{BOPO}=\frac{\text { Biaya Operasional }}{\text { Pendapatan Operasional }} \times 100 \%
$$

BOPO adalah rasio yang mengukur besarnya biaya operasional yang digunakan pihak bank dalam rangka menghasilkan pendapatan operasional bank.

e) ROA

$$
\mathrm{ROA}=\frac{\text { Net Income }}{\text { Average of Total Assets }} \times 100 \%
$$

Return on asset digunakan untuk mengukur kemampuan manajemen dalam memperoleh profitabilitas dan manajerial efisiensi secara keseluruhan.

\section{Metode Analisis Data}

Dalam penelitian ini, penyajian deskriptif dilakukan perhitungan rata-rata (mean), data maksimum, data minimum, dan standar deviasi dari data yang telah dikumpulkan sebelumnya. Analisis yang digunakan untuk melihat pengaruh variabel bebas terhadap variabel terikat dalam penelitian ini yaitu uji beda atau uji-t. Uji t yang digunakan yaitu Uji Paired Sample ttest. Uji Paired t-test adalah metode yang digunakan untuk membandingkan dua kelompok mean dari sampel yang berpasangan. Dalam penelitian ini, data panel yang terdiri dari 100 unit observasi, dibagi ke dalam dua kelompok data yaitu data total kredit, rasio kredit UMKM terhadap total kredit, NPL, BOPO dan ROA tahun 2008-2012 yaitu sebelum PBI Nomor 14/22/PBI/2012 berlaku dan data pada periode tahun 2013-2017 setelah PBI Nomor 14/22/PBI/2012 berlaku. Pengujian hipotesis dilakukan dengan membandingkan nilai thitung dengan $\mathrm{t}_{\text {tabel: }}$

a. Jika $t_{\text {hitung }}<\mathrm{t}_{\text {tabel}}$, maka $\mathrm{H}_{0}$ diterima dan Ha ditolak

b. Jika thitung $>\mathrm{t}_{\text {tabel}}$, maka $\mathrm{H}_{0}$ ditolak dan Ha diterima.

Selain itu, pengambilan keputusan juga dapat dilihat dari taraf signifikan P-value (onetailed). Jika $\mathrm{p}>0,05$ maka $\mathrm{H}_{0}$ diterima dan jika $\mathrm{p}<0,05$ maka $\mathrm{H}_{0}$ ditolak.

\section{HASIL DAN KESIMPULAN}

Hasil penelitian berupa analisis deskriptif dari Total Kredit yang diberikan, Rasio Kredit UMKM terhadap Total Kredit, NPL, BOPO dan ROA sebelum dan sesudah PBI Nomor 14/22/PBI/2012 berlaku adalah sebagai berikut:

\begin{tabular}{llllll}
\hline PERIODE & TOTAL KREDIT & RASIO KREDIT UMKM & NPL & BOPO & ROA \\
\hline $2008-2012$ & 10,1 TRILYUN & $23,12 \%$ & $1,57 \%$ & $73,33 \%$ & $3,35 \%$ \\
$2013-2017$ & 22,2 TRILYUN & $18,03 \%$ & $3,30 \%$ & $70,57 \%$ & $1,73 \%$
\end{tabular}

Hasil uji hipotesis penelitian dengan uji-t menunjukkan hasil sebagai berikut:

\begin{tabular}{lll}
\hline Variabel Terikat & t-hitung & Keterangan \\
Total Kredit & 10,261 & Signifikan pada $\alpha=0,05$ \\
Rasio Kredit UMKM & $-2,275$ & Tidak Signifikan pada $\alpha=0,05 *$ \\
NPL & 3,882 & Signifikan pada $\alpha=0,05$ \\
BOPO & $-1,469$ & Tidak signifikan pada $\alpha=0,05$ \\
ROA & $-9,519$ & Tidak Signifikan pada $\alpha=0,05 *$ \\
t-tabel $=1,676 ; \mathrm{n}=50 ; \mathrm{df}=49$ & $* t$-tabel $=1,680 ; \mathrm{n}=45 ; \mathrm{df}=44$
\end{tabular}


Hasil pengujian hipotesis menunjukkan bahwa rata-rata Total Kredit BPD sampel pada periode setelah PBI Nomor 14/22/PBI/2012 tentang penyaluran kredit UMKM diberlakukan secara signifikan lebih besar daripada Total Kredit BPD sampel pada periode sebelum PBI tersebut berlaku. Namun, hasil penelitian menunjukkan bahwa terdapat penurunan rata-rata rasio penyaluran kredit UMKM terhadap keseluruhan kredit pada BPD sampel dari kurun waktu 2008-2012 ke 2013-2017. BPD sampel menyalurkan persentase kredit UMKM dari total keseluruhan kredit yang lebih kecil pada periode 2013-2017, yaitu periode setelah PBI Nomor 14/22/PBI/2012 tentang penyaluran kredit UMKM berlaku dibandingkan dengan periode 2008-2012 sebelum peraturan bank Indonesia tersebut berlaku. Peraturan yang diharapkan dapat meningkatkan persentase penyaluran kredit UMKM memang telah membuat beberapa BPD yang penyaluran kredit UMKM-nya di bawah nilai minimum yang ditentukan untuk menambah volume penyaluran kredit UMKM mereka. Namun, di sisi lain, peraturan ini justru membuat Bank yang telah menyalurkan UMKM di atas ambang minimum yang ditentukan dalam PBI cenderung menurunkan rasio penyaluran kredit di sektor UMKM dan hanya menyalurkan kredit UMKM sekitar batas minimum yang ditentukan. Hal ini terindikasi dari rata-rata rasio penyaluran kredit UMKM yang semakin mendekati nilai batas minimum 15\% yaitu pada nilai rata-rata $18,03 \%$.

Dalam kaitannya dengan risiko, hasil penelitian menunjukkan bahwa terdapat peningkatan rata-rata NPL yang cukup tinggi dari kurun waktu 2008-2012 ke 2013-2017. Uji hipotesis juga menunjukkan bahwa rata-rata NPL sampel pada periode 2013-2017, secara signifikan lebih tinggi daripada NPL BPD sampel pada periode 2008-2012. Hal ini menunjukkan bahwa BPD sampel mengalami lebih banyak kredit yang tidak (kurang lancar) pada periode 2013-2017 dibandingkan dengan periode 2008-2012. Sementara terjadi penurunan rasio penyaluran kredit UMKM, peningkatan NPL yang terjadi dapat dikarenakan oleh disalurkannya atau dialokasikannya kredit tersebut pada sektor lain seperti kredit korporasi dan kredit retail lainnya dengan risiko yang justru lebih besar dari kredit sektor UMKM. Rossi dkk (2009) menyimpulkan bahwa kenaikan NPL ini juga bisa dikarenakan oleh manajemen yang kekurangan waktu atau keahlian untuk melakukan monitoring pinjaman termasuk proses pemberian kredit pada debitur, sehingga tingkat penyaluran kredit yang lebih tinggi tidak selalu menjamin risiko kredit yang lebih rendah. Alasan lain adalah kualitas dan komposisi portfolio kredit. Hasil penelitian ini menunjukkan, total penyaluran kredit yang besar perlu diimbangi dengan upaya peningkatan kualitas dan komposisi kredit. Sementara itu, tidak ada perbedaan yang signifikan antara rata-rata BOPO sampel pada periode 2013-2017, setelah PBI Nomor 14/22/PBI/2012 berlaku, dengan BOPO BPD sampel pada periode 20082012 sebelum PBI tersebut berlaku. Hal ini menunjukkan bahwa beban operasional terhadap pendapatan operasional BPD sampel tidak banyak terpengaruh oleh adanya penyaluran kredit UMKM dalam kedua periode tersebut. Hal ini dapat dijelaskan oleh fakta bahwa banyak BPD tidak banyak menambah personil khusus untuk menyalurkan kredit UMKM. Di beberapa BPD seperti Bank DKI dan Bank BJB, misalnya memang terdapat unit khusus untuk kredit UMKM seperti Warung Mikro BJB dan Gerai Mikro Bank DKI. Namun demikian, jumlahnya yang belum banyak tidak signifikan mempengaruhi BOPO. Seluruh BPD sampel juga mengalami penurunan ROA. Uji hipotesis menunjukkan bahwa terdapat penurunan rata-rata ROA BPD sampel pada periode 2013-2017 dibandingkan dengan ROA BPD sampel pada periode 20082012. Hal ini menunjukkan bahwa BPD sampel mengalami keuntungan atau profitabilitas yang lebih sedikit pada periode 2013-2017. Meskipun BOPO tidak meningkat atau tidak membebani, hasil yang menunjukkan bahwa terdapat peningkatan NPL, mengindikasikan bahwa penurunan profitabilitas yang terjadi dapat dikarenakan oleh tingginya NPL ini. Hal ini juga sesuai dengan temuan Tehulu (2016) yang menunjukkan bahwa profitabilitas memiliki hubungan negatif yang signiifkan terhadap risiko kredit.

Dapat disimpulkan bahwa berkaitan dengan adanya kewajiban Bank Umum termasuk BPD di dalamnya untuk menyalurkan kredit UMKM dengan ketentuan minimum seperti 
tertuang dalam PBI Nomor 14/22/PBI/2012, pelaksanaan peraturan tersebut berpengaruh terhadap meningkatnya total kredit yang disalurkan (loans), namun rasio penyaluran kredit UMKM menurun. Dalam kurun waktu sebelum dan sesudah PBI tersbeut berlaku, terdapat peningkatan risiko yang signifikan (yang dikur dengan NPL) serta penurunan profitabilitas yang signifikan pula (diukur dengan ROA) pada Bank Pembangunan Daerah sampel. Namun, peraturan tersebut tidak berpengaruh terhadap efisiensi yang diukur dengan BOPO. Dalam kaitannya dengan penyaluran kredit UMKM, ada dua hal yang berimplikasi pada NPL dan profitabilitas Bank. Di satu sisi, kredit UMKM yang pada umumnya memiliki jangka masa pinjaman pendek lebih memungkinkan tingkat pembayaran yang lancar dibandingkan jenis kredit lain. Di sisi lain, non-performing loan (NPL) sektor UMKM dapat terus meningkat karena pinjaman tidak dijamin dengan agunan, sehingga Bank atau Lembaga Keuangan umumnya terpapar risiko kredit yang tinggi. Hal ini sesuai dengan temuan Shu-Teng, Zariyawati, Suraya-Hanim dan Annuar (2015). Sehingga penelitian selanjutnya, dapat mempelajari suatu studi kasus dimana penyaluran kredit UMKM pada suatu Bank dilihat secara lebih terperinci termasuk tenor pinjaman dan kualitas pinjaman yang diberikan kepada nasabah.

\section{DAFTAR PUSTAKA}

Bank Indonesia. Peraturan Bank Indonesia Nomor 14/22/PBI/2012.

Kar, A.K. and Swain, R.B. (2014). Interest Rates and Financial Performance of Microfinance Institutions: Recent Global Evidence. The European Journal of Development Research, 26, 87-106. https://doi.org/10.1057/ejdr.2013.33

Lisdayanti, A., Daniel, R., \& Anindita, W. (2013). Efektifitas Kinerja BPD Terhadap Pertumbuhan Ekonomi Daerah. Proceeding Pesat (Psikologi, Ekonomi, Sastra, Arsitektur \& Teknik Sipil), vol. 5.

Revindo, M. D., \& Gan, C. (2017). Rural Microfinance Banking Viability and Outreach: A Case of Bank Rakyat Indonesia. In C. Gan \& G.V. Nartea (Eds.), Microfinance in Asia (pp. 337-356). New Jersey: World Scientific.

Rossi, S., Schwaiger, M., Winkler, \& G. (2009). How loan portfolio diversification affects risk, efficiency and capitalization: a managerial behavior model for Austrian banks. Journal of Banking \& Finance 32, 2218-2226.

Shu-Teng, L., Ashhari, M., Zariyawati, Suraya-Hanim, M., \& Nassir, A. (2015). Determinants of Microfinance Repayment Performance: Evidence from Small Medium Enterprises in Malaysia. International Journal of Economics and Finance, 7(11), 110-120.DOI: 10.5539/ijef.v7n11p110.

Siamat, D. (2005). Manajemen Lembaga Keuangan Kebijakan Moneter dan Perbankan Edisi Kelima. Jakarta: Lembaga Penerbit Fakultas Ekonomi Universitas Indonesia.

Tehulu, T.A. (2013) Determinants of financial sustainability of microfinance institutions in East Africa, European Journal of Business and Management, Vol. 5, No. 17, pp. 152158.

Undang-Undang Nomor 20 Tahun 2008 tentang UMKM. 